\title{
Dr Herbert Barker (1814-1865) of Bedford and infant hygiene
}

\author{
Peter M Dunn
}

Thomas Herbert Barker was born in 1814. He received his medical education at Queen's College, Birmingham and also at University College, London, where for a time he was house surgeon to $\mathrm{Mr}$ Liston. He received the licence of the Apothecaries' Company in 1837 and membership of the Royal College of Surgeons in 1842; the fellowship followed in 1851. Meanwhile he had obtained the MD, University of London. $\mathrm{He}$ was also later awarded the Fothergillian gold medal of the Medical Society of London for an essay on malaria and, in 1865, the Hastings gold medal for another essay on Deodorization and Disinfection. The prize was presented by $\mathrm{Sir}$ Charles Hastings himself at a meeting of the BMA that year in Leamington.

Barker settled in Bedford where he served as general practitioner, obstetrician, surgeon, physician, paediatrician, pathologist, and public health doctor. His knowledge was very comprehensive and he aimed for and achieved the highest standard in everything in which he took an interest. He was immensely hard working and determined and the goodness of his intentions, his high intellect, and his unwearied industry on behalf of the community gained for him a wide reputation and honour for his profession. $\mathrm{He}$ founded the Bedford Dispensary, a food kitchen, and a coal club for the poor, and he took a great interest in the affairs of the various hospitals in the town. His greatest contribution, though, was in improving the sanitation of the town. In 1854 he startled the inhabitants with a pamphlet entitled: 'Is Bedford healthy? and if not, why not? and how can it be made so?' Another essay had the title: 'Foul Air and Fever, as exemplified in the sanitary condition of Bedford'. Against considerable opposition he persevered and eventually succeeded in winning support for the improvements needed to prevent disease in the town.

Dr Barker wrote many papers and essays. In 1859 he published an important, though little known work on the hygienic management of infants and children. ${ }^{1}$ As he wrote:

University of Bristol, Southmead Hospital

Correspondence to:

Professor P M Dunn,

Department of Child Health,

Southmead Hospital,

Southmead Road, Bristol

BS10 5NB.
'During several years past I have devoted some part of the leisure afforded by an extensive practice to the task of collecting information on the errors most prevalent with regard to the management of infants and children ... I would contend, the right management of infants and children lies at the root of all
ON TIIE

\section{HYGIENIC MANAGEMENT}

\section{INFANTS AND CHILDREN.}

ar

T. HERBERT BdRKER, M.D.Lond.,

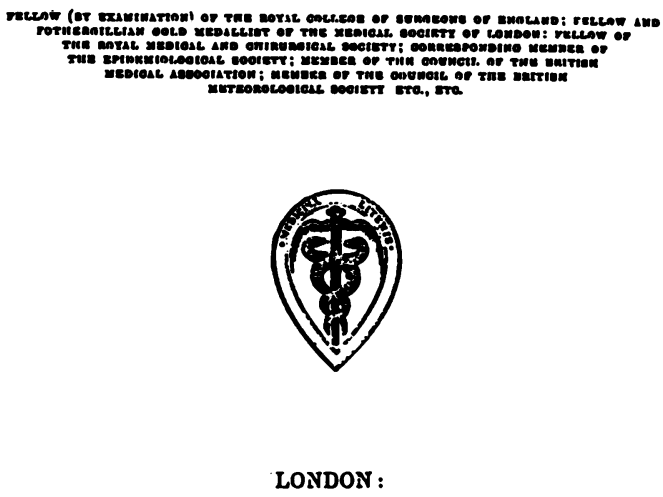

JOHN CHURCHILI, NẸT BURLINGTON STREET.

x.pecesux.

Title page of Dr Barker's text, 1859.

other plans of social amelioration. What can good subsequent measures avail, for a constitution already hopelessly injured by errors in the opening years of life?

Half of all the children born in England die before they reach their fifth birthday ... What are the causes of this excessive mortality? They may be found under the following general divisions:- First. Original constitutional debility, or hereditary disease. Secondly. Acute diseases, such as measles, hooping-cough, scarlet fever, etc. Thirdly. Our general want of sanitary measures, giving rise to pollution of the atmosphere. Fourthly. Mismanagement with regard to diet and regimen in the nursery. Of these four causes of mortality, the first three are common to all ages: the last alone is peculiar to infancy ... To this last cause of infantile 
mortality I shall exclusively devote attention ... The reason for thus giving it priority is, that I regard it as surely and easily preventible; and the object is, to point out the two simple means of its prevention: (1) An increased attention to the subject on the part of medical men; (2) Sound instructions for mothers and nurses.

The topics belonging to infantile hygiene should, it is conceived, form no inconsiderable part of every course of lectures on midwifery and disease of children. Unfortunately, these topics, seeming so simple and easy that few will take the pains to study them, are, too often, passed over lightly and briefly ... The medical man who could save life even in a rare case of surgical difficulty, may sacrifice the life of a healthy infant for want of knowledge of a few plain natural laws of diet and regimen!'

The following extracts serve to illustrate Dr Barker's simple yet practical and very important advice on newborn care:

'In every period of life, health depends, in a great measure, on the equable diffusion of warmth over the whole body, ... the newborn infant should be warmly wrapped in flannel; that during cold weather it should be dressed near a comfortable fire, ... Too much attention can hardly be paid to cleanliness during infancy and childhood. Careful washing should be performed daily ... care should be taken not to allow exposure of the body to cold. We have known bad results to follow too protracted exposure in washing, and tardy movements in dressing the child ... The temperature of the morning and evening bath should be about $90^{\circ}$ or $96^{\circ}$ Fahr.; and on no account should the infant be submitted to cold bathing during the first few weeks of its existence ... The nursery should be a large room, airy, well-ventilated and easily warmed; neatly painted and papered ... an upper room is preferable ... Let it be scoured once a week ... special attention should be given to have the room filled with fresh air every morning ... Attention must also be paid to the due regulation of temperature ... we must pay regard to the influence of light ... the early period of infancy is passed in sleep ... the only natural interruption to repose is the feeling of hunger. The lesson to be learned from this fact is obvious - all unnecessary interruptions of the child's natural state of rest should be avoided ...'

Barker's comments on infant feeding also have a remarkably modern ring to them:

'In cases where, happily, it is resolved that the child shall have its natural diet, some hours, or perhaps days, may elapse before the secretion of milk is ready ... in ordinary circumstances an infant is well able to bear a fast of twelve hours immediately after its birth. In this interval, while the flow of the mother's milk is deferred, the nurse is too commonly anxious to supply the supposed want by pouring gruel or panada into the child's stomach ... This process is useless and mischievous ... There can be no need of any artificial food, if, during the first five or six months, the infant is applied to the breast at regular intervals of about three or four hours, by night as well as by day ... There may be cases in which it would be highly improper to allow the mother to suckle her own babe, while it may be difficult to employ the services of a good wet-nurse. In such a case, we must, with the utmost caution, employ a system of artificial feeding. $A$ very considerable part of the mortality of infants reared by hand is the result of errors, respecting either the quality or the quantity of the artificial food administered ... the artificial food of infancy should form the best possible imitation of the natural milk which ought to be the diet of the infant. In order to succeed in this imitation, we must carefully study the properties of the original. Milk is the perfect form in which nature presents to us the three essential constituents, saccharine, oily, and albuminous matters, necessary to support infant life. It may be resolved into three organised compounds, which we may designate by the familiar terms, cream, curd and whey. These three constituents vary in proportions in the milk of various animals, as the following table will show:

\begin{tabular}{|c|c|c|c|c|}
\hline Properties. & Human. & Cor's mills. & Goat's milk. & Asses' mill. \\
\hline $\begin{array}{l}\text { Casein } \ldots \ldots \ldots \ldots \ldots \\
\text { Butter } \ldots \ldots \ldots \ldots \ldots \\
\text { Sngar } \ldots \ldots \ldots \ldots \ldots \\
\text { Snline matters } \ldots \\
\text { Water } \ldots \ldots \ldots \ldots \ldots\end{array}$ & $\begin{array}{r}2 \cdot 05 \\
5 \cdot 20 \\
6 \cdot 34 \\
0 \cdot 45 \\
85 \cdot 00\end{array}$ & $\begin{array}{r}1 \cdot 48 \\
3 \cdot 13 \\
1 \cdot 77 \\
0 \cdot 00 \\
87 \cdot 02\end{array}$ & $\begin{array}{r}4 \cdot 02 \\
3 \cdot 32 \\
5 \cdot 28 \\
0 \cdot 58 \\
80 \cdot 80\end{array}$ & $\begin{array}{r}1.82 \\
0.11 \\
0.08 \\
0.31 \\
01.05\end{array}$ \\
\hline Total & $100 \cdot 00$ & $100 \cdot 0 n$ & $100 \cdot 00$ & $100 \cdot 00$ \\
\hline
\end{tabular}

Now it should be observed that this casein is the least digestible of the constituents of milk; and from this fact we learn the necessity of diluting cow's milk, so as to adapt it to the tender organisation of the child ... The foregoing table also shows us that it is proper to add to the diluted cow's milk a small quantity of loaf sugar, to increase its resemblance in the saccharine quality, to the milk supplied for the child by nature ... Let the diet of the infant be gently given in small quantities. Let the first symptom of indifference be noticed as a sign that the appetite is satisfied for the present'.

Outside medicine Herbert Barker had many interests in which he excelled, including chemistry, meteorology, microscopy, astronomy, antiques, and also exploration of the Alps which he visited every summer. He married twice and had six children. Sadly, in view of his efforts to improve the hygiene of Bedford, he contracted typhoid there and died four weeks later at the early age of 51 .

1 Barker TH. On the hygienic management of infants and children. London: J Churchill, 1859. 